04.1

\title{
Исследование относительной реакционной способности ароматических соединений в воздухе под действием плазмы импульсного разряда
}

\author{
(C) И.Е. Филатов, В.В. Уварин, Д.Л. Кузнецов
}

Институт электрофизики УрО РАН, Екатеринбург, Россия

E-mail: fil@iep.uran.ru

Поступило в Редакцию 16 июня 2021 г.

В окончательной редакции 16 июня 2021 r.

Принято к публикации 21 июля 2021 г.

На основе метода конкурирующих реакций разработана методика определения относительной реакционной способности паров ароматических соединений по отношению к компонентам плазмы импульсного коронного разряда. На модельных смесях на основе бензола, толуола и ксилола с содержанием 250-500 pрm получены параметры относительной реакционной способности ароматических соединений в потоке воздуха и азота. Показано влияние водяного пара на процесс. Полученные данные будут полезны для оптимизации процессов плазмохимической очистки воздуха от паров токсичных ароматических соединений.

Ключевые слова: коронный разряд, ароматические соединения, неравновесная плазма атмосферного давления, очистка воздуха, летучие органические соединения, ВТЕХ.

DOI: 10.21883/PJTF.2021.22.51718.18924

Ароматические органические соединения - летучие органические соединения (ЛОС), являющиеся важными токсичными компонентами вентиляционных выбросов промышленных предприятий. Для очистки воздуха от них разрабатываются методы, использующие неравновесную плазму электрических разрядов различного типа [1-6]. Значительная часть исследований посвящена толуолу как одному из наиболее распространенных представителей ароматических соединений или группы BTEX (benzene, toluene, ethylbenzene, xylene) фракции, получаемой в коксохимическом производстве [7-10]. Ввиду многообразия модификаций методов и способов представления результатов данные этих исследований сложно сравнивать. Это связано с отсутствием единого унифицированного подхода к выбору параметров, являющихся критериями эффективности процессов. Нами показано, что использование модельных смесей соединений позволяет получать относительные параметры реакционной способности ЛОС с высокой точностью [11,12]. Эффективность использования энергии разряда характеризуется плазмохимическим выходом формального реагента. Эти параметры могут являться величинами, необходимыми для сравнения альтернативных методов и масштабирования процессов.

В настоящей работе представлены результаты исследования относительной реакционной способности распространенных ароматических соединений (бензола, толуола и $o$-ксилола) по отношению к компонентам плазмы, генерируемой в воздухе за счет действия импульсного коронного разряда. Для исследований применялись компоненты как раздельно, так и вместе. Находясь в равных условиях, соединения конкурируют за участие в реакциях с компонентами плазмы, в результате чего параметр реактивности может быть определен с высокой точностью, а скорость быстрых процессов оценена с помощью метода газожидкостной хроматографии [13].

Методика эксперимента и установка подробно описаны в $[11,13]$. Аналитические процедуры аналогичны [13]. Генератор импульсов высокого напряжения был построен по схеме с использованием SOS-коммутаторов [14]. Разряд имел следующие параметры: напряжение амплитудой $100 \mathrm{kV}$, ток амплитудой $490 \mathrm{~A}$, длительность импульса на полувысоте $20 \mathrm{~ns}$, частота следования импульсов $10 \mathrm{~Hz}$. Разрядная часть плазмохимического реактора состояла из цилиндра из нержавеющей стали с внутренним диаметром $85 \mathrm{~mm}$ и длиной $56 \mathrm{~cm}$, вдоль оси которого был натянут потенциальный электрод из стальной проволоки диаметром $0.24 \mathrm{~mm}$. Объем газовой системы установки составлял $V=261$. Энергия импульса измерялась как среднее значение за серию импульсов и составляла $0.55-0.65$ J. Эксперимент включал обработку разрядом в течение 2-5 min, анализ содержания озона и ЛОС в течение $3 \mathrm{~min}$. В качестве смеси, моделирующей воздух, использовалась коммерческая газовая смесь „Синтетический воздух“ с составом $\left[\mathrm{N}_{2}\right]:\left[\mathrm{O}_{2}\right]=80: 20$ (по объему).

На рис. 1, a показаны концентрации ароматических компонентов - бензола (1), толуола (2) и $o$-ксилола (3) - с начальными концентрациями по 500 pрm в зависимости от удельной энергии $E$ (в единицах $\mathrm{J} / 1$ ), т.е. от количества энергии, вкладываемой в единицу объема газовой смеси. Опыты проводились для каждого компонента отдельно. В каждом случае измерялась концентрация озона $\left[\mathrm{O}_{3}\right]$; соответствующие зависимости содержания озона обозначены как 4.1-4.3. Для сравнения показана наработка озона в воздухе 


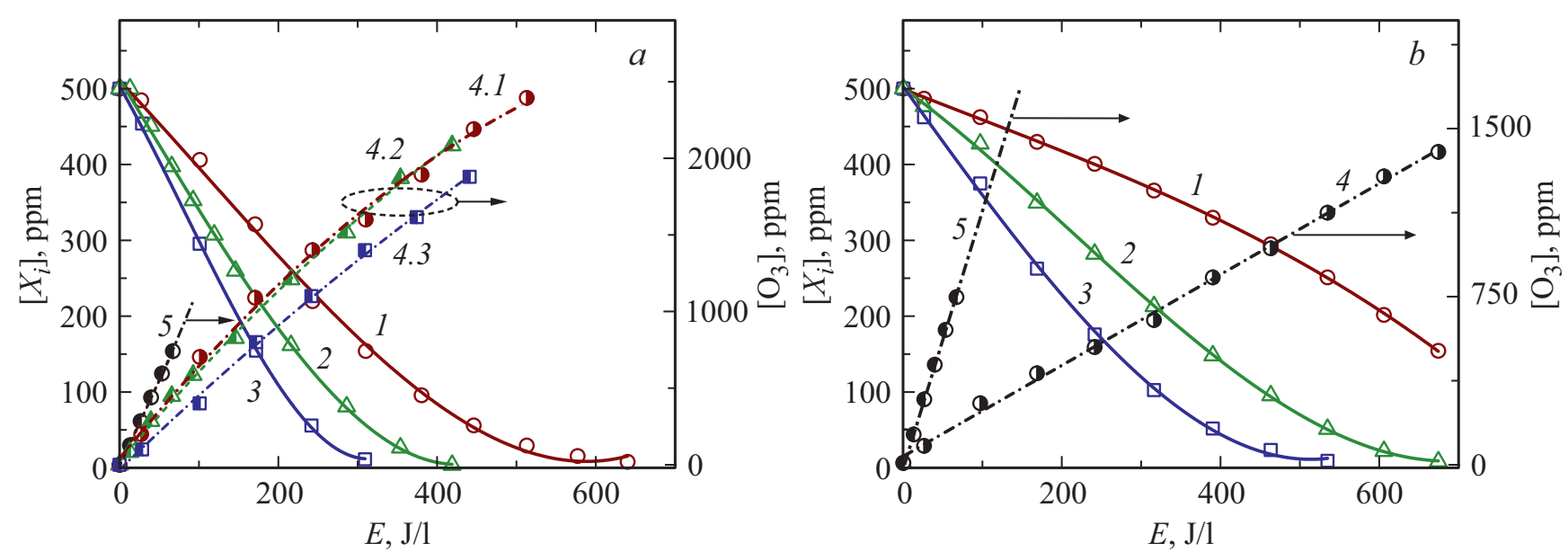

Рис. 1. $a-$ изменение концентраций $\left[X_{i}\right]$ и $\left[\mathrm{O}_{3}\right]$ в зависимости от удельной энергии $E$ в воздухе для бензола $(1)$, толуола $(2)$, $o$-ксилола (3), озона в присутствии бензола (4.1), озона в присутствии толуола (4.2), озона в присутствии $o$-ксилола (4.3), озона в чистом воздухе $(5) . b-$ изменение концентраций $\left[X_{i}\right]$ и $\left[\mathrm{O}_{3}\right]$ в зависимости от удельной энергии $E$ в воздухе при одновременном присутствии компонентов при начальном содержании каждого из компонентов 500 pрm для бензола $(1)$, толуола $(2), o$-ксилола $(3)$, озона (4), озона в чистом воздухе (5). Точки - эксперимент, линии - аппроксимация полиномом второй степени.
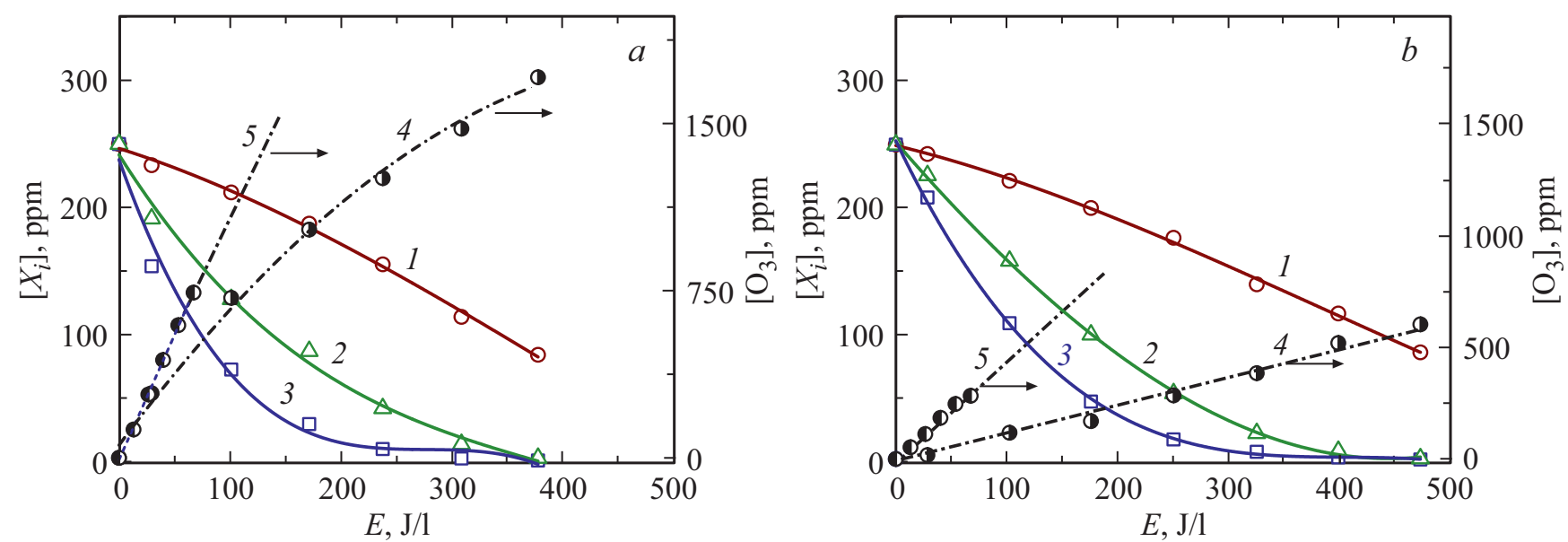

Рис. 2. $a-$ изменение концентраций $\left[X_{i}\right]$ и $\left[\mathrm{O}_{3}\right]$ в зависимости от удельной энергии $E$ в воздухе при одновременном присутствии компонентов при начальном содержании каждого из компонентов $250 \mathrm{ppm}$ для бензола (1), толуола (2), o-ксилола (3), озона (4), озона в чистом воздухе (5). $b$ - то же при добавлении 2 vol.\% паров $\mathrm{H}_{2} \mathrm{O}$. Точки - эксперимент, линии - аппроксимация полиномом второй степени.

без примесей (5). Видно, что ароматические соединения обладают различной реакционной способностью по отношению к компонентам плазмы. Для того чтобы выяснить относительную реакционную способность, согласно методу [13] все компоненты добавлялись в газовую смесь одновременно. Так, на рис. $1, b$ показаны зависимости концентраций ароматических соединений при их одновременном содержании в смеси при начальном содержании каждого из компонентов 500 ppm. На рис. 2,a показаны аналогичные зависимости при начальном содержании компонентов по $250 \mathrm{ppm}$. Для выяснения влияния роли паров воды проведен эксперимент (рис. $2, b$ ), аналогичный по условиям представленному на рис. $2, a$, но с добавлением 2 vol. $\% \mathrm{H}_{2} \mathrm{O}$. На рис. 3 приведены результаты эксперимента с азотом в качестве основного компонента газовой смеси.

Для выявления основных закономерностей, представленных на рис. 1-3, вычислялись значения, характеризующие энергетические параметры процессов и факторы относительной реакционной способности компонентов. Данные аппроксимировались полиномами второй степени, аппроксимация представлена линиями. Из наклонов зависимостей может быть вычислен плазмохимический выход того или иного процесса $G_{i}$ (в единицах $\mathrm{mol} / 100 \mathrm{eV}$ ) с учетом коэффициента пересчета размерностей, представленных на рисунках: $1 \mathrm{ppm} \cdot 1 \cdot \mathrm{J}^{-1}=0.433 \mathrm{~mol} / 100 \mathrm{eV}$. Выход озона обозначается как $G_{\mathrm{O}_{3}}$ для воздуха и $G_{\mathrm{O}_{3}}+X_{i}$ для воздуха, содер- 
Плазмохимические выходы и относительная реакционная способность ароматических соединений

\begin{tabular}{|c|c|c|c|c|c|c|c|c|c|}
\hline \multirow{3}{*}{$\begin{array}{c}\text { Источник } \\
\text { информации }\end{array}$} & \multirow{3}{*}{$\begin{array}{c}\text { Компонент } \\
X_{i}\end{array}$} & \multirow{3}{*}{$\begin{array}{l}{\left[X_{0}\right],} \\
\text { ppm }\end{array}$} & \multirow{3}{*}{ Газ } & \multicolumn{4}{|c|}{$G, \mathrm{~mol} / 100 \mathrm{eV}$} & \multirow{3}{*}{$k_{i}$} & \multirow{3}{*}{$k_{i, t o l}$} \\
\hline & & & & \multicolumn{2}{|c|}{$G_{\mathrm{O}_{3}}$} & \multirow[b]{2}{*}{$-G_{i}$} & \multirow[b]{2}{*}{$-\sum G_{i}$} & & \\
\hline & & & & Воздух & $\begin{array}{c}\text { Воздух } \\
+X_{i}\end{array}$ & & & & \\
\hline рис. $1, a$ & $\begin{array}{l}\text { Бензол } \\
\text { Толуол } \\
\text { Ксилол }\end{array}$ & $\begin{array}{l}500 \\
500 \\
500\end{array}$ & Воздух & $\begin{array}{l}4.85 \\
4.85 \\
4.85\end{array}$ & $\begin{array}{l}2.65 \\
2.65 \\
2.16\end{array}$ & $\begin{array}{l}0.51 \\
0.73 \\
0.91\end{array}$ & $\begin{array}{l}0.51 \\
0.73 \\
0.91\end{array}$ & $\begin{array}{l}3.0 \\
5.0 \\
7.0\end{array}$ & $\begin{array}{l}0.6 \\
1.0 \\
1.4\end{array}$ \\
\hline рис. $1, b$ & $\begin{array}{c}\text { Бензол } \\
\text { Толуол } \\
\text { Ксилол }\end{array}$ & $\begin{array}{l}500 \\
500 \\
500 \\
\end{array}$ & Воздух & 4.85 & 0.81 & $\begin{array}{l}0.18 \\
0.39 \\
0.60 \\
\end{array}$ & 1.17 & $\begin{array}{l}0.88 \\
2.16 \\
3.86 \\
\end{array}$ & $\begin{array}{l}0.44 \\
1.00 \\
1.78 \\
\end{array}$ \\
\hline рис. $2, a$ & $\begin{array}{l}\text { Бензол } \\
\text { Толуол } \\
\text { Ксилол }\end{array}$ & $\begin{array}{l}250 \\
250 \\
250\end{array}$ & Воздух & 4.85 & 2.35 & $\begin{array}{l}0.16 \\
0.38 \\
0.44 \\
\end{array}$ & 0.98 & $\begin{array}{c}1.78 \\
6.7 \\
14.3 \\
\end{array}$ & $\begin{array}{l}0.26 \\
1.00 \\
2.13\end{array}$ \\
\hline рис. $2, b$ & $\begin{array}{c}\text { Бензол } \\
\text { Толуол } \\
\text { Ксилол }\end{array}$ & $\begin{array}{l}250 \\
250 \\
250\end{array}$ & $\begin{array}{c}\text { Воздух } \\
+2 \text { vol. } \% \mathrm{H}_{2} \mathrm{O}\end{array}$ & 1.89 & 0.56 & $\begin{array}{l}0.13 \\
0.36 \\
0.45\end{array}$ & 0.94 & $\begin{array}{l}1.31 \\
5.25 \\
9.3\end{array}$ & $\begin{array}{l}0.26 \\
1.00 \\
1.77\end{array}$ \\
\hline рис. 3 & $\begin{array}{l}\text { Бензол } \\
\text { Толуол } \\
\text { Ксилол }\end{array}$ & $\begin{array}{l}250 \\
250 \\
250\end{array}$ & $\mathrm{~N}_{2}$ & $\begin{array}{l}- \\
- \\
-\end{array}$ & $\begin{array}{l}- \\
- \\
-\end{array}$ & $\begin{array}{l}0.20 \\
0.36 \\
0.43\end{array}$ & 0.98 & $\begin{array}{l}2.26 \\
4.92 \\
6.77\end{array}$ & $\begin{array}{l}0.45 \\
1.00 \\
2.13\end{array}$ \\
\hline
\end{tabular}

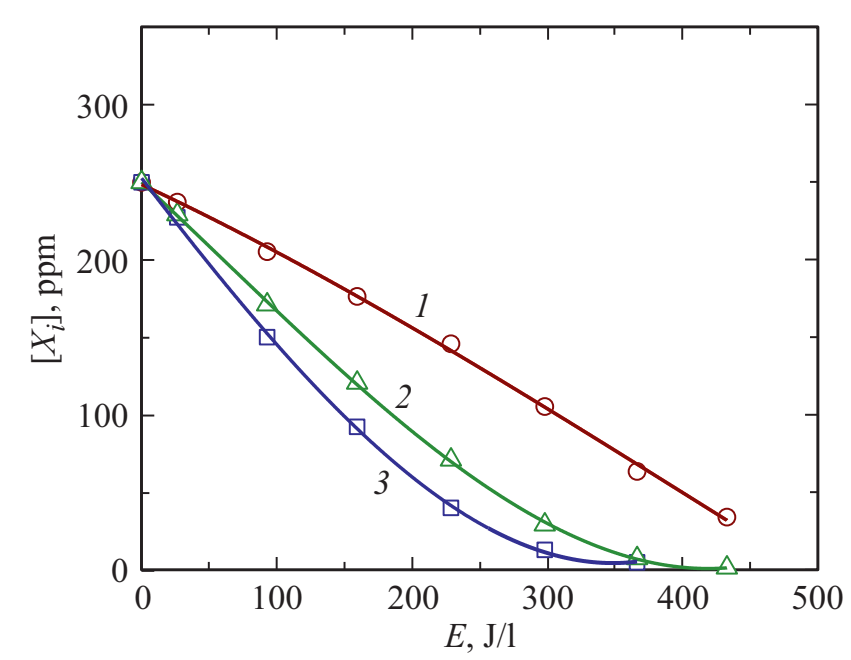

Рис. 3. Изменение концентраций $\left[X_{i}\right]$ в зависимости от удельной энергии $E$ в азоте при одновременном присутствии компонентов для бензола (1), толуола (2), o-ксилола (3). Точки - эксперимент, линии - аппроксимация полиномом второй степени.

жащего примеси $X_{i}$. Соответственно процесс удаления примесей характеризуется отрицательной величиной $G_{i}$, в то время как $G_{\mathrm{O}_{3}}$ имеет положительное значение. Энергетическая эффективность метода характеризуется суммарной величиной: $G=\sum G_{i}$. Константы, характеризующие реакционную способность компонентов $i$, вычислялись по формуле $k_{i}=G_{i} /\left[X_{i}\right]$. Для сравнения реакционных способностей двух компонентов исполь- зовалось выражение $k_{j} / k_{i}=G_{j} /\left[X_{j}\right] /\left(G_{i} /\left[X_{i}\right]\right)$, вычисления проводились в начальной области, для $E=100 \mathrm{~J} / 1$. В качестве компонента сравнения использовался толуол как наиболее распространенное и исследуемое ЛОС, для которого $k_{i}=k_{t o l}$, и вычислялись факторы относительной реакционной способности относительно него как $k_{i, t o l}=k_{i} / k_{t o l}$. Значения для всех указанных величин представлены в таблице. В условиях раздельных компонентов (рис. 1,a) процесс удаления каждой примеси конкурирует только с процессом дезактивации активных частиц плазмы, что видно по некоторому выравниванию значений относительной реакционной способности (последний столбец). При совместном присутствии компоненты конкурируют между собой и относительные реакционные способности толуола, бензола и ксилола соотносятся как 0.44:1.0:1.78. При снижении концентрации компонентов до $250 \mathrm{ppm}$ происходит изменение соотношения относительной реакционной способности от бензола в пользу ксилола: 0.26:1.0:2.13 соответственно. Кажущееся отклонение от закона действующих масс позволяет выявлять наличие разных механизмов удаления компонентов исследуемой смеси. Наработка озона $G_{\mathrm{O}_{3}}$ в воздухе без примесей может являться количественной характеристикой эффективности данной выбранной экспериментальной установки и применяться для оптимизации ее электрофизических параметров. Как свидетельствуют данные таблицы, удаление одной молекулы ароматического соединения приводит к уменьшению количества озона на 2.5-4 молекулы, что значительно выше, чем в случае непредельных соединений, где соотношение близко к стехиометрическому $[15,16]$. 
Введение паров воды значительно уменьшает выход озона, однако энергетическая эффективность удаления примесей меняется незначительно и относительная реакционная способность примерно такая же. Эти данные позволяют считать, что процессы с участием активных форм кислорода имеют второстепенное значение при удалении ароматических соединений. Исследования процессов в смесях на основе азота подтверждают это: относительная реакционная способность меняется незначительно, как и общий плазмохимический выход. Таким образом, реакционная способность ароматических соединений по отношению к компонентам плазмы увеличивается с ростом количества метильных групп, что подтверждает данные [10]. Процессы с участием активных форм азота при удалении ароматических соединений имеют важное значение, что согласуется с данными [8].

Описываемый метод использования смесей ЛОС позволяет оперативно оценивать относительные реакционные способности летучих ароматических соединений и может являться инструментом для выявления различных механизмов удаления плазмохимическими методами ЛОС разной химической структуры.

\section{Финансирование работы}

Работа выполнена при частичной поддержке Российского фонда фундаментальных исследований и Правительства Свердловской области (проекты № 20-48660062 р_а и 20-08-00882).

\section{Конфликт интересов}

Авторы заявляют, что у них нет конфликта интересов.

\section{Список литературы}

[1] A.M. Vandenbroucke, R. Morent, N. De Geyter, C. Leys, J. Hazard. Mater., 195 (15), 30 (2011). DOI: 10.1016/J.JHAZMAT.2011.08.060

[2] W. Lu, Y. Abbas, C. Pan, H. Wang, M.F. Mustafa, Front. Environ. Sci. Eng., 13 (2), 30 (2019). DOI: $10.1007 / \mathrm{s} 11783-019-1108-5$

[3] C. Du, X. Gong, Y. Lin, J. Air Waste Manag. Assoc., 69 (8), 879 (2019). DOI: 10.1080/10962247.2019.1582441

[4] S. Li, X. Dang, X. Yu, G. Abbas, Q. Zhang, L. Cao, Chem. Eng. J., 388, 124275 (2020). DOI: 10.1016/j.cej.2020.124275

[5] W.C. Chung, D.H. Mei, X. Tu, M.B. Chang, Catal. Rev. Sci. Eng., 61 (2), 270 (2019).

DOI: $10.1080 / 01614940.2018 .1541814$

[6] A.A. Adelodun, J. Ind. Eng. Chem., 92, 41 (2020). DOI: $10.1016 /$ j.jiec.2020.08.026

[7] N. Jiang, L. Guo, C. Qiu, Y. Zhang, K. Shang, N. Lu, Y. Wu, Chem. Eng. J., 350, 12 (2018). DOI: 10.1016/j.cej.2018.05.154

[8] A.N. Trushkin, M.E. Grushin, I.V. Kochetov, N.I. Trushkin, Yu.S. Akishev, Plasma Phys. Rep., 39 (2), 167 (2013). DOI: $10.1134 / \mathrm{S} 1063780 \mathrm{X} 13020025$

[9] L. Hou, X. Li, D. Xie, H. Wang, Molecules, 23 (4), 890 (2018). DOI: $10.3390 /$ molecules 23040890
[10] T. Shou, N. Xu, Y. Li, G. Sun, M.T. Bernards, Y. Shi, Y. He, Plasma Chem. Plasma Process., 39 (4), 863 (2019). DOI: $10.1007 / \mathrm{s} 11090-019-09986-5$

[11] И.Е. Филатов, В.В. Уварин, Д.Л. Кузнецов, ЖТФ, 88 (5), 702 (2018). DOI: 10.21883/JTF.2018.05.45898.2421 [I.E. Filatov, V.V. Uvarin, D.L. Kuznetsov, Tech. Phys., 63 (5), 680 (2018). DOI: 10.1134/S1063784218050079].

[12] I.E. Filatov, V.V. Urvarin, D.L. Kuznetsov, J. Phys.: Conf. Ser., 1147, 012122 (2019). DOI: $10.1088 / 1742-.6596 / 1147 / 1 / 012122$

[13] И.Е. Филатов, В.В. Уварин, Д.Л. Кузнецов, Письма в ЖТФ, 46 (2), 47 (2020). DOI: 10.21883/PJTF.2020.02.48954.17922 [I.E. Filatov, V.V. Uvarin, D.L. Kuznetsov, Tech. Phys. Lett., 46 (1), 94 (2020). DOI: 10.1134/S1063785020010216].

[14] S.N. Rukin, Rev. Sci. Instrum., 91 (1), 011501 (2020). DOI: $10.1063 / 1.5128297$

[15] I. Filatov, V. Uvarin, D. Kuznetsov, in IEEE 2020 7th Int. Congress on energy fluxes and radiation effects (EFRE) (IEEE,2020), p. 317. DOI: $10.1109 /$ EFRE47760.2020.9242056

[16] I. Filatov, V. Uvarin, D. Kuznetsov, in IEEE 2020 7th Int. Congress on energy fluxes and radiation effects (EFRE) (IEEE, 2020), p. 322.

DOI: $10.1109 /$ EFRE47760.2020.9242070 